\title{
Alternativas tecnológicas para o tratamento e disposição final dos resíduos de serviços de saúde
}

Technological alternatives for the treatment and final disposal of waste from health services

\author{
Ana Paula Mendes Geitenes', Cristina Maria Dacach Fernandez Marchi"
}

\begin{abstract}
RESUMO
O Atualmente vivemos inúmeras transformações, percebe-se que o estilo de vida das pessoas, vem provocando modificações. Um exemplo bastante atual dessas modificações são os resíduos sólidos, que vem comprometendo a qualidade ambiental, e, a qualidade de vida do homem a julgar pelos impactos socioeconômicos, sanitários e ambientais a eles inerentes. Os resíduos dos serviços de saúde (RSS) se inserem dentro desta problemática e vêm assumindo grande importância nos últimos anos. Esta preocupação cresceu devido ao conhecimento sobre os riscos impostos à saúde pública e ao meio ambiente. O presente estudo objetivou apresentar alternativas tecnológicas no tratamento e na disposição final utilizados na gestão de RSS. Trata-se de um estudo descritivo simples, de cunho bibliográfico. A coleta de dados, foi alcançada por meio de informações junto à bibliotecas eletrônicas. Percebe-se, no entanto que, existem inúmeras tecnologias de tratamento de RSS, com diferentes características, em termos de custos, segurança ao meio ambiente e à população, entre outros. Nota-se que aqueles processos que apresentam custo baixo, não são considerados seguros e biodegradáveis e que há necessidade de conhecer todas as características desses processos para que haja uma escolha do tratamento mais adequado, podendo variar essa adequação.
\end{abstract}

Palavras-chave: Resíduos de serviços de saúde; Alternativas tecnológicas; Tratamento; Disposição final

\section{ABSTRACT}

\begin{abstract}
A Today we live many transformations, it is perceived that the lifestyle of people, has been causing changes. A very recent example of these changes are solid waste, which has compromised environmental quality, and the quality of life of man judging by the socioeconomic, health and environmental impacts inherent to them. The residues of the health services (RSS) are part of this problem and have been assuming great importance in recent years. This concern has grown due to knowledge about the risks posed to public health and the environment. The present study aimed to present technological alternatives in the treatment and final disposal used in RSS management. This is a simple, bibliographic descriptive study. Data collection was achieved through information from the electronic libraries. It is noticed, however, that there are many technologies of RSS treatment, with different characteristics, in terms of costs, safety to the environment and the population, among others. It should be noted that those processes that have a low cost are not considered safe and biodegradable and that there is a need to know all the characteristics of these processes so that there is a choice of the most appropriate treatment, and this suitability may vary.
\end{abstract}

Keywords: Health services waste; Technological alternatives; Treatment and final disposal

\section{INTRODUÇÃO}

Atualmente vivemos inúmeras transformaçóes, percebe-se que o estilo de vida das pessoas, vem provocando modificaçóes estruturais no ambiente que nos rodeia, como forma de adequar tais espaços as necessidades e exigências do homem. Um exemplo bastante atual dessas modificaçóes são os resíduos sóli-

'Fisioterapeuta, Mestranda em Planejamento Ambiental da Universidade Católica do Salvador (UCSAL), Professora assistente da Universidade Católica do Salvador (UCSAL), Salvador, BA, Brasil.ana.mendes@pro.ucsal.br

"Administradora, Doutora em Geologia, Mestre em Planejamento Urbano, Professora adjunta da Universidade Católica do Salvador (UCSAL), Salvador, BA, Brasil. cristina.marchi@pro.ucsal.br 
dos, onde o aumento de sua geração vem comprometendo a qualidade ambiental, e, a qualidade de vida do homem a julgar pelos impactos socioeconômicos, sanitários e ambientais a eles inerentes.

Nos últimos anos, houve um aumento da preocupação com relação à gestão dos resíduos dos serviços de saúde (RSS) a nível mundial, tendo sido direcionado um esforço significativo no sentido da realizaçáo de uma gestão adequada e segura dos resíduos perigosos advindos dos serviços de saúde. Esta preocupação cresceu devido ao conhecimento obtido nas últimas décadas sobre os riscos impostos à saúde pública e ao meio ambiente. Está comprovado que os resíduos gerados pelos serviços de saúde podem ser perigosos, tóxicos e até mesmo letais devido ao seu alto potencial de transmissão de doenças (MAVROPOULOS, 2010).

De acordo com os resultados da pesquisa desenvolvida pela Associação Brasileira de Empresas de Limpeza Pública e Resíduos Especiais (ABRELPE), no ano de 2016, 4.495 municípios brasileiros prestaram os serviços de coleta, tratamento e disposição final de 256.238 toneladas de RSS, o equivalente a $1,24 \mathrm{~kg}$ por habitante/ano. O dado atual representa uma redução de $1,5 \%$ em relação ao total gerado em 2015 e de 2,3\% no valor per capita. Representando inclusive uma redução na geração de RSS do ano de 2015 para 2016, seguindo o mesmo movimento decrescente na geração dos demais grupos de resíduos sólidos (ABRELPE, 2017).

O gerenciamento dos resíduos de serviços de saúde (GRSS), anteriormente à criação da Agência Nacional de Vigilância Sanitária (ANVISA), era regulamentado somente por resolução do Conselho Nacional do Meio Ambiente (CONAMA). Devido à competência legal estabelecida pela Lei 9.782/1999, que criou a ANVISA, coube a esta agência a competência de regulamentar os procedimentos internos dos serviços de saúde, relativos ao GRSS. O Sistema Nacional de Vigilância Sanitária (SNVS) atua de forma descentralizada, e a fiscalização do GRSS compete às Vigilâncias Sanitárias dos Estados, Municípios e do DF, com o auxílio dos órgãos ambientais locais, auxiliados pelos Serviços de Saneamento e dos Serviços de Limpeza Urbana. Considera-se que parte dos resíduos gerados apresenta risco similar aos domiciliares, podendo ter o mesmo destino, esgoto ou aterro sanitário.

Dessa forma, a ANVISA publicou a RDC no 306 em 2004, sobre GRSS, com a finalidade de estabelecer os procedimentos internos nos serviços geradores de RSS e compatibilizar com a resolução do CONAMA 358/2005, pois as resoluçóes anteriores divergiam em certos aspectos.

Passados alguns anos da entrada em vigor da RDC 306/2004, devido aos questionamentos recebidos durante esse tempo, bem como a evolução das tecnologias e ainda a entrada em vigor da Lei

12.305/2010, que instituiu a Política Nacional de Resíduos Sólidos (PNRS), verificou-se a necessidade de revisar essa RDC e publicar uma nova normativa que contemple as novidades legais e tecnológicas que surgiram nesse período.

Sendo assim foi publicada a Resolução ANVISA/RDC 222, em 28 de março de 2018, que regulamenta as boas práticas de gerenciamento dos resíduos de serviços de saúde e orientar vigilâncias sanitárias locais e serviços geradores de resíduos de serviços de saúde no correto cumprimento da norma, a norma somente entrará em vigor em 25/09/2018, quando irá revogar a Resolução ANVISA/RDC 306/04 (ANVISA, 2018).

A Lei n. ${ }^{\circ}$ 12.305/2010 institui a Política Nacional de Resíduos Sólidos (PNRS), dispondo sobre seus princípios, objetivos e instrumentos, bem como sobre as diretrizes relativas à gestão integrada e ao gerenciamento de resíduos sólidos, incluídos os perigosos, às responsabilidades dos geradores e do poder público e aos instrumentos econômicos aplicáveis. Estão sujeitas à observância desta as pessoas físicas ou jurídicas, de direito público ou privado, responsáveis, direta ou indiretamente, pela geração de resíduos sólidos e as que desenvolvam açóes relacionadas à gestão integrada ou ao gerenciamento de resíduos sólidos. Esta Lei não se aplica aos rejeitos radioativos, que são regulados por legislação específica. Aplicam-se aos resíduos sólidos, além do disposto nesta lei, nas leis no $11.445 / 2007,9.974 / 2000$, e 9.966/2000, as normas estabelecidas pelos órgãos do Sistema Nacional do Meio Ambiente (Sisnama), do Sistema Nacional de Vigilância Sanitária (SNVS), do Sistema Unificado de Atenção à Sanidade Agropecuária (Suasa) e do Sistema Nacional de Metrologia, Normalização e Qualidade Industrial (Sinmetro) (BRASIL,2010).

Dentre as orientações normativas atuais sobre RSS, a PNRS estabelece que para determinados grupos destes resíduos (Grupo A - resíduos com possível presença de agentes biológicos) há necessidade do tratamento previamente à sua disposiçáo final. No entanto, cerca de $25,7 \%$ dos municípios brasileiros ainda destinaram os RSS coletados sem declarar o tratamento prévio; contrariando as normas vigentes, além de explicitar os riscos aos trabalhadores envolvidos no gerenciamento destes resíduos, à saúde pública e ao meio ambiente (ABRELPE, 2017).

As alternativas tecnológicas mais modernas, não apresenta um único método de tratamento ou dis- 
posição final que elimine completamente todos os riscos para o ambiente, em geral a depender do tipo de tecnologia, os resíduos são transformados de uma fase para outra. Com relaçáo, a reduzir o risco associado a microrganismos, o objetivo mais importante é destruí-los antes da liberação do material contaminado ao meio ambiente. A destruição de patógenos pode ser através de tratamento térmico, químico e irradiador apropriado (GEITENES, 2018).

Dentro do contexto acima descrito, constatou-se a necessidade e a importância de buscar, na literatura nacional, o que tem sido publicado sobre as alternativas tecnológicas mais comuns no tratamento e na disposição final utilizados na gestão adequada dos RSS, abrangendo os impactos ambientais e os custos operacionais dessas tecnologias Além disso, a partir de uma revisão narrativa de literatura, pode-se estimular a produçáo de novos estudos com enfoque nesse assunto, com vistas a fortalecer as discussóes nesse campo do saber.

Assim, este estudo objetiva apresentar as alternativas tecnológicas para o tratamento e disposição final dos RSS, no período de 2005 a 2017, relativos à gestão adequada dos RSS.

\section{METODOLOGIA}

Trata-se de um estudo descritivo através de uma revisão narrativa de literatura. A busca bibliográfica foi desenvolvida por meio de informaçóes em bibliotecas virtuais, no portal da Scientific Eletronic Library Online (SCIELO), Pubmed e base de dados: Elsevier SciVerse ScienceDirect, SciVerse Scopus. Essa busca procedeu-se em maio de 2017, utilizando os seguintes descritores: resíduos de serviços de saúde, alternativas tecnológicas, tratamento e disposição final.

Foram incluídos artigos científicos, dissertações e teses que abordam a temática sobre Resíduos Sólidos de Saúde, publicados entre 2005 a 2017 nos idiomas Português e Inglês. Produções não disponíveis gratuitamente na íntegra e de forma virtual foram excluídas.

Para acesso ao texto completo, foram usados os seguintes recursos: link disponível diretamente nas bases de dados, busca no portal do periódico em que o artigo, dissertaçáo ou tese foi publicado, busca no portal CAPES e buscador Google.

A análise das informaçôes foi realizada por meio de leitura exploratória e analítica do material encontrado.

\section{DISCUSSÃO}

\section{I CONCEITOS E DEFINIÇÕES}

Os Resíduos de Serviços de Saúde (RSS) são todos aqueles resultantes de atividades exercidas nos serviços de saúde, por suas características, necessitam de processos diferenciados em seu manejo, exigindo ou nâo tratamento prévio à sua disposição final (GEITENES, 2018).

Os resíduos de serviços de saúde são definidos segundo as resoluçóes ANVISA RDC n. ${ }^{\circ}$ 306/2004 e CONAMA n. ${ }^{\circ}$ 358/3005, como sendo todos aqueles gerados pelos serviços relacionados com o atendimento à saúde humana ou animal, como hospitais, clínicas, postos de saúde, consultórios médicos, dentários e veterinários, inclusive os serviços de assistência domiciliar e de trabalhos de campo; laboratórios analíticos de produtos para a saúde; necrotérios, funerárias, serviços onde se realizem atividades de embalsamento, serviços de medicina legal, drogarias e farmácias inclusive as de manipulação; estabelecimentos de ensino e pesquisa na área da saúde; centro de controle de zoonoses; distribuidores de produtos farmacêuticos, importadores, distribuidores, produtores de materiais e controles para diagnóstico in vitro; unidades móveis de atendimento à saúde; serviços de acupuntura, serviços de tatuagem e similares (ANVISA, 2004).

Atualmente, a Resolução ANVISA RDC n.o 222/2018 estabelece Boas Práticas de Gerenciamento dos Resíduos de Serviços de Saúde a todos os geradores, cujas atividades derivem de entidades públicas, privadas, filantrópicas, civis ou militares, incluindo aquelas que exercem açóes de ensino e pesquisa.

Outro ponto em destaque dessa Resoluçáo se refere à abrangência de quem são os geradores de RSS, agora incluídos: serviços de piercing e salóes de beleza e estética (ANVISA, 2018). Dada as particularidades das fraçóes perigosas dos RSS, destaca-se no Quadro 1 conceitos sobre riscos biológicos, químicos e físicos:

A classificação dos grupos de RSS - que se encontram em conformidade com a RDC n. ${ }^{\circ}$ 306/2004 - ANVISA e Resolução n. ${ }^{\circ}$ 358/2005 - CONAMA, demonstrado no Quadro 2, abaixo; 
Quadro 1 - Conceitos sobre riscos biológicos, químicos e físicos

\begin{tabular}{|c|c|}
\hline Riscos Biológicos & $\begin{array}{l}\text { É um organismo, ou substância oriunda de um organismo que traz alguma ameaça } \\
\text { (principalmente) à saúde humana. Constituem risco biológico os RSS, amostras } \\
\text { de microrganismos, vírus ou toxinas de origem biológica que causam impacto na saúde } \\
\text { humana, cujos agentes sáo classificados em: } \\
\text { a) classe de risco 1: baixo risco individual para o trabalhador e para a coletividade, com } \\
\text { baixa probabilidade de causar doença ao ser humano; } \\
\text { b) classe de risco 2: risco individual moderado para o trabalhador e com baixa } \\
\text { probabilidade de disseminaçáo para a coletividade. Podem causar doenças ao ser humano, } \\
\text { para as quais existem meios eficazes de profilaxia ou tratamento; } \\
\text { c) classe de risco 3: risco individual elevado para o trabalhador e com probabilidade de } \\
\text { disseminaçáo para a coletividade. Podem causar doenças e infecçóes graves ao ser humano, } \\
\text { também existem meios eficazes de profilaxia ou tratamento; e } \\
\text { d) classe de risco 4: risco individual elevado para o trabalhador e com probabilidade } \\
\text { elevada de disseminaçáo para a coletividade. Apresenta grande poder de transmissibilidade } \\
\text { de um individuo a outro. Podem causar doenças graves ao ser humano, para as quais nâo } \\
\text { existem meios eficazes de profilaxia ou tratamento. }\end{array}$ \\
\hline Riscos Químicos & $\begin{array}{l}\text { É entendido como a probabilidade do organismo entrar em contato (exposiçấo } \\
\text { crônica ou acidental) com o agente químico (substâncias, compostos ou produtos) } \\
\text { por via respiratória (poeiras, fumos, névoas, neblinas, gases ou vapores), pela pele } \\
\text { ou por ingestảo. }\end{array}$ \\
\hline Riscos Físicos & $\begin{array}{l}\text { Săo aqueles relacionados às condiçóes atmosféricas (temperaturas extremas como } \\
\text { calor, frio e umidade) que podem provocar danos no individuo. Incluem também } \\
\text { os riscos provenientes de ruídos, iluminaçáo, eletricidade, pressóes anormais, } \\
\text { vibraçóes, radiaçóes ionizantes e náo ionizantes tais como ondas eletromagnéticas e } \\
\text { ondas de rádio, o infrassom e o ultrassom. }\end{array}$ \\
\hline
\end{tabular}

Fonte: Adaptado do Ministério do Trabalho e Emprego. Riscos Biológicos: guia técnico. Os riscos biológicos no âmbito da norma regulamentadora no 32 (BRASIL,2006)

Quadro 2 - Classificação e Caracterização dos RSS

\begin{tabular}{|l|l|}
\hline \multicolumn{1}{|c|}{ Grupos } & Caracterizaçáo \\
\hline $\begin{array}{l}\text { Grupo A - resíduos com risco } \\
\text { de biológico }\end{array}$ & $\begin{array}{l}\text { Resíduos com a possível presença de agentes biológicos que, por } \\
\text { suas características de maior virulência ou concentraçáo, podem } \\
\text { apresentar risco de infeç̧ấo. Exemplos: placas e lâminas de } \\
\text { laboratório, carcaças, peças anatômicas (membros), tecidos, bolsas } \\
\text { transfusionais contendo sangue; dentre outras. }\end{array}$ \\
\hline $\begin{array}{l}\text { Grupo B - resíduos com risco } \\
\text { químico }\end{array}$ & $\begin{array}{l}\text { Resíduos contendo substâncias químicas que podem apresentar } \\
\text { risco a saúde pública ou ao meio ambiente, dependendo de suas } \\
\text { características de inflamabilidade, corrosividade, reatividade e } \\
\text { toxicidade. Exemplos: medicamentos apreendidos, reagentes de } \\
\text { laboratório, resíduos contendo metais pesados, dentre outros. }\end{array}$ \\
\hline
\end{tabular}

Continua.... 
Quadro 2 - Conclusão....

\begin{tabular}{|c|c|}
\hline Grupos & Caracterizaçáo \\
\hline $\begin{array}{l}\text { Grupo } \quad \mathrm{C} \quad-\quad \text { rejeitos } \\
\text { radioativos }\end{array}$ & $\begin{array}{l}\text { Materiais resultantes de atividades humanas que contenham } \\
\text { radionuclídeos em quantidades superiores aos limites de eliminaçáo } \\
\text { especificados nas normas da CNEN e para os quais a reutilizaçáo é } \\
\text { imprópria ou nâo prevista; exemplos: rejeitos radioativos ou } \\
\text { contaminados com radionuclídeos, medicina nuclear e radioterapia. }\end{array}$ \\
\hline Grupo D - resíduos com & $\begin{array}{l}\text { Resíduos que năo apresentam risco biológico, químico ou } \\
\text { radiológico a saúde ou ao meio ambiente, podendo ser equiparados } \\
\text { aos resíduos domiciliares; exemplos: papéis de uso sanitário e fraldas, } \\
\text { restos de alimentos, resíduos de áreas administrativas e de limpeza } \\
\text { geral, materiais recicláveis, gesso. }\end{array}$ \\
\hline $\begin{array}{l}\text { Grupo E - resíduos } \\
\text { perfurocortantes }\end{array}$ & $\begin{array}{l}\text { Materiais perfurocortantes ou escarificantes, exemplos: lâminas em } \\
\text { geral, agulhas, escalpes, ampolas de vidro, brocas, espátulas, entre } \\
\text { outros }\end{array}$ \\
\hline
\end{tabular}

Fonte: Adaptado do RDC n.o 306/2004 - ANVISA e Resolução n.o 358/2005 - CONAMA

\subsection{Tratamento dos Resíduos de Serviços de Saúde}

O tratamento dos RSS consiste na aplicação de método, técnica ou processo que altere as peculiaridades dos riscos próprios dos resíduos, amortizando ou extinguindo o risco de contaminação, de acidentes de trabalho ou de agravos à natureza (GEITENES, 2018).

As discussóes sobre a necessidade de tratamento de todos os RSS no Brasil vêm ocorrendo desde a proposição da norma da Associação Brasileira de Normas Técnicas (ABNT) no 12.808/1993 (Gerenciamento de resíduos de serviços de saúde intra estabelecimento) e seguiram, posteriormente, por meio das Resoluçôes do CONAMA no 05/1993 e no 283/2001. A alternativa de definição pelo tratamento de todos os RSS mais parece estar pautada no mito do risco elevado de contaminaçóes e desenvolvimento de doenças infecciosas provenientes dos estabelecimentos de saúde do que, de fato, no cunho científico (MOL, 2017; SILVA, 2011). A Resolução no 283/2001 e a Resolução no $05 / 1993$, nas disposiçóes que tratam de resíduos sólidos oriundos de serviços de saúde, foram revogadas pela Resolução no 358/2005.

A Resolução CONAMA no 358/2005, publicada especificamente para o tratamento de RSS, foi editada considerando os princípios da prevenção, da precaução, do poluidor pagador, da correção na fonte e de integração entre os vários órgãos envolvidos para fins do licenciamento e da fiscalização. Esta resolução considera também a necessidade de minimizar riscos ocupacionais nos ambientes de trabalho e proteger a saúde do trabalhador e da população em geral, bem como considera a necessidade de estimular a minimização da geração de resíduos, promovendo a substituição de materiais e de processos por alternativas de menor risco, a redução na fonte e a reciclagem, dentre outras. Além disso, considera que a segregação dos resíduos, no momento e local de sua geração, permite reduzir o volume de resíduos que necessitam de manejo diferenciado (BRASIL, 2005; SILVA, 2011).

Borg (2007) enfatizou em seu artigo que muitas das regulamentaçóes sobre a gestão de RSS vigentes em vários países foram construídas por meio de pressão política e percepçóes populares, tendo pouca base científica. Os documentos elaborados pela Society for Healthcare Epidemiology of America (SHEA) indicam a existência de regulamentaçóes sobre RSS sem base científica e, muitas vezes, confundem conceitos a respeito dos riscos químicos e biológicos. De fato, uma parcela dos RSS possui periculosidade e necessita de tratamento, porém tal quantitativo representa em torno de 15\% do total dos RSS (WHO, 2015). O restante é similar aos resíduos sólidos domiciliares. 
O tratamento pode ser feito no estabelecimento gerador ou em outro local, desde que observadas, nestes casos, as condiçóes de segurança para o transporte entre o estabelecimento gerador e o local do tratamento. Quando realizada no próprio estabelecimento esta fase é denominada de pré-tratamento ou tratamento prévio. São vários os métodos alternativos de tratamento de resíduos que podem possibilitar a disposição do resíduo em aterro sanitário (GEITENES, 2018).

Existem diversas tecnologias disponíveis no Brasil e no mundo para tratamento de RSS, porém a mais apropriada será aquela que melhor representar a combinação entre eficiência do tratamento e custo energético. São elas: esterilização a vapor, esterilização a seco, esterilização por radiaçôes ionizantes, esterilização por gases, esterilização por ondas eletromagnéticas (microondas, ondas de rádio), autoclave/ tratamento térmico úmido, esterilização por plasma, desinfecção química, desinfecção química/mecânica e incineração (NOVI, 2013).

\subsection{INCINERAÇÃO}

O tratamento térmico com oxidação ou incineração é definido como o processo de oxidação dos materiais, a altas temperaturas, sob condições controladas, onde os componentes são reduzidos a resíduos não combustíveis, resultando na geração de cinzas, escória e gases. Por meio de sua utilização é possível tratar quase todos os tipos de resíduos, principalmente os infecciosos, patológicos e perfurocortantes (MAVROPOULOS, 2010).

Sendo assim, este é o processo mais difundido para tratamentos de resíduos, além disso, é aconselhado como o mais adequado para garantir a eliminação de microrganismos patogênicos presentes na massa dos resíduos, desde que sejam atendidas as necessidades de projeto e operação adequadas ao controle do processo. É adotada por técnicos da área como a forma mais apropriada de tratamento de resíduos de serviço de saúde, sendo considerada muitas vezes, também como forma de destinação final. Os incineradores modernos apresentam duas câmaras de combustão, uma primária e uma secundária, equipadas por queimadores capazes de alcançar a combustão completa dos resíduos e uma ampla destruiçáo das substâncias químicas nocivas e tóxicas, como dioxinas, entre outros (SOUZA, 2011).

A tecnologia de incineração tem se desenvolvido para atender às legislaçôes ambientais de redução de emissóes atmosféricas e deve se encontrar de acordo com a hierarquia dos resíduos prevista na PNRS, uma vez que esta tecnologia possibilita a extração da energia contida nos resíduos sólidos para produção de eletricidade, calor ou vapor, minimizando assim a quantidade de resíduos enviados aos aterros sanitários. Isto caracteriza uma modalidade de recuperaçáo energética de resíduo (FERREIRA, 2013; BOSMANS, 2013).

Algumas vantagens e desvantagens inerentes ao processo de incineração são descritas a seguir no Quadro 3:

Quadro 3 - Vantagens e desvantagens do tratamento por incineração

\begin{tabular}{|c|c|}
\hline Vantagens & Desvantagens \\
\hline 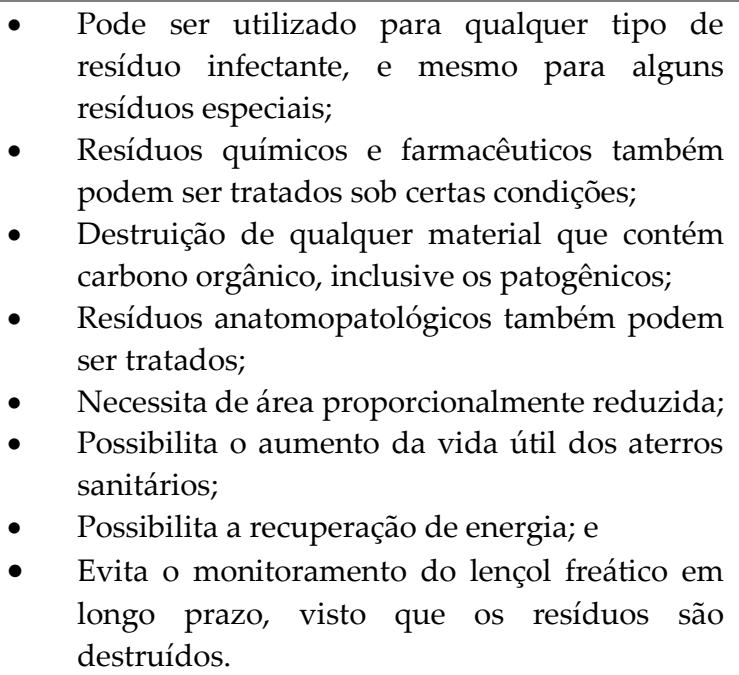 & $\begin{array}{l}\text { - Custo de implantação do sistema é duas ou três } \\
\text { vezes mais do que qualquer outro; } \\
\text { - Necessita alto custo de funcionamento pelo } \\
\text { consumo de combustível e grandes } \\
\text { investimentos em medidas de controle } \\
\text { ambiental; } \\
\text { Dificuldade de manutenção e operação, } \\
\text { exigindo pessoal especializado e de queima de } \\
\text { resíduos com umidade alta; } \\
\text { Possibilidade de risco de emissões de } \\
\text { substâncias tóxicas na atmosfera; } \\
\text { Os RSS apresentam teores de enxofre e cloretos } \\
\text { que podem produzir dióxido de enxofre e ácido } \\
\text { clorídrico na reação de combustão, esses gases } \\
\text { são expelidos em incineradores mal projetados } \\
\text { ou operados; }\end{array}$ \\
\hline
\end{tabular}

Fonte: Adaptado de COUTINHO et al., 2011; SOUZA, 2011; MAVROPOULOS, 2010 


\subsubsection{AutocLAVE}

A autoclavagem é um processo de esterilização a vapor que quando aplicada a RSS, mediante a combinação de vapor saturado sob pressão superior à atmosférica e calor, se obtém a descontaminação de resíduos infectantes, com a destruição de microrganismos, inclusive esporos, mediante a termo coagulação das proteínas citoplasmáticas (DIAZ et al., 2005)

Esse método é bastante utilizado, com a intenção de esterilizar, os artigos críticos e semicríticos; entretanto sua utilização, para os RSS, passou a ocorrer recentemente, principalmente em países de avançada gestão de resíduos sólidos, sendo utilizada no Brasil principalmente para resíduos biológicos. Só é eficiente se os resíduos tiverem uma preparação prévia, que permita homogeneização, permitindo que o vapor atinja toda superfície do resíduo, e impedindo barreiras que dificultem a propagaçáo do calor. Além disso, esse processo se limita à aplicação em pequenas escalas, visto que, as unidades de tratamento do Brasil, não conseguem ter inúmeras autoclaves, nem mesmo autoclaves de grande porte, não permitindo assim a esterilização do total de resíduos produzidos, dados os custos de investimento nos equipamentos (GEITENES, 2018).

\subsubsection{MiCROONDAS}

Nesse processo os resíduos são previamente triturados, depois levados a uma câmara de tratamento, recebendo aí, uma injeção de vapor para umedecê-los e, entấo, uniformizar essa umidade, a alta temperatura $\left(130^{\circ} \mathrm{C}\right)$. Logo após, os resíduos passam por um campo de microondas, ondas estas eletromagnéticas de alta frequência, que produzem vibraçóes. O processo, porém não é recomendado para grandes quantidades de resíduos de serviço de saúde, e também para resíduos anatômicos. Existe, ainda, o risco de emissóes de aerossóis que podem conter produtos orgânicos perigosos. Esse sistema de tratamento é muito utilizado no tratamento local dos resíduos de laboratórios e são constituídos por fornos pequenos, cujo princípio de funcionamento é o mesmo dos fornos de microondas de uso doméstico (SOUZA, 2011).

\subsubsection{Desativação Eletrotérmica (ETD)}

É a tecnologia de tratamento mais utilizada no município de São Paulo, é caracterizada pela deposição dos resíduos a um fosso altamente fechados, e sob pressão negativa, e posteriormente é realizada a dupla trituração dos resíduos, seguida pela exposição destes a um campo elétrico de alta potência gerado por ondas eletromagnéticas de baixa frequência, atingindo altas temperaturas, podendo chegar a $95^{\circ} \mathrm{C}$ (MARTINI, 2016).

\subsubsection{PIRÓLISE}

A pirólise também conhecido como craqueamento na indústria do petróleo, a pirólise é um tratamento energeticamente auto sustentável, já que não necessita energia externa, onde seus sistemas atingem temperaturas de até $3000^{\circ} \mathrm{C}$, através de energia térmica, de combustíveis fósseis ou energia elétrica. Para o tratamento de resíduos de serviço de saúde, o processo de inativação dos microrganismos infecciosos se dá pela decomposição química de suas moléculas, ao serem os resíduos biocontaminados submetidos a um calor intenso em ambiente controlado. É um processo de decomposição química por calor na ausência de oxigênio, seu balanço energético é positivo, ou seja, produz mais energia do que consome. O processo consiste na trituraçáo dos resíduos que são previamente selecionados. Após esta etapa, os resíduos vão para o reator pirolítico onde através de uma reação endotérmica ocorrerão as separaçóes dos subprodutos em cada etapa do processo (FILHO et al., 2014).

A pirólise tem um custo financeiro médio por ter flexibilidade na operação de combustível e reduzir consideravelmente o volume para disposição. A sustentabilidade do sistema é alta, pois produz como subproduto o biocarvão que pode ser utilizado como fertilizante no solo, por ser uma tecnologia que trata termicamente na ausência de oxigênio, há a redução de compostos poluentes atmosféricos, a eficiência térmica e elétrica é alta em comparação as outras tecnologias, visto que a gaseificação são as tecnologias com capacidade para geração de eletricidade, desse modo à visão social é mediana por apresentar baixo ruído, menor demanda de área requerida e gerar eletricidade a partir de resíduos (KUHL et al., 2015; TÔRRES, 2014).

A pirólise tem vantagens ambientais que são a degradação térmica em atmosfera com menor nível estequiométrico de oxigênio, assim minimiza as emissóes de dioxinas e furanos, promove a redução de volume e descaracterizaçáo do resíduo, garantindo melhor desempenho ambiental em comparaçáo a outras tecnologias (FILHO et al, 2014).

A pirólise lenta a tambor rotativo opera com temperaturas variando de $400^{\circ} \mathrm{C}$ a $850^{\circ} \mathrm{C}$, onde os resíduos são dispostos em um tambor que gira lentamente movimentando estes de uma extremidade a outra, possuindo aquecimento externo ao tambor, evitando assim a presença de oxigênio livre dentro do reator. Os resíduos devem ter granulometria até a ordem 
de $50 \mathrm{~mm}$ o que garante a flexibilidade no tratamento de uma grande variedade de resíduos, ocorrendo a transformação destes em gás de síntese que posteriormente é purificado para que possa ser utilizado em grupos geradores para geração de eletricidade. Esta limpeza promove ganho na eficiência elétrica e redução na emissão de poluentes (REICHERT, 2012).

Este tratamento produz de 85 a $90 \%$ de gás de síntese e de 10 a 15\% de biochar, sendo que estes dois produtos da pirólise lenta apresentam cunho econômico, tendo como produção de eletricidade e fertilizante biológico as suas principais aplicaçóes (CHAMON; CARDOSO; BARROS, 2013). O biochar também denominado biocarvão tem sido pesquisado e tendo confirmado os benefícios no solo como, aumento da capacidade de troca catiônica promovendo melhoria na fertilidade do solo, além de aumentar a retençáo de água e reduzir a lixiviaçáo de nitrogênio em aguas subterrâneas sendo uma alternativa propicia para correçóes no solo (MAIA, MADARI \& NOVOTNY, 2011).

Estas unidades de tratamento ainda não estão em prática no Brasil, desta forma, não estão totalmente difundidas. Embora seja considerado superior à incineração, tanto na eficiência térmica, quanto no controle de efluentes, este não seja adequado à heterogeneidade dos RSS.

\subsubsection{PLASMA TÉRMICO}

O plasma térmico é uma tecnologia emergente, com alta capacidade energética e capacidade de queimas a altas temperatura, comumente utilizada em metalurgia que, quando aplicado a RSS, destrói os microrganismos pela açáo de um gás ionizado a alta temperatura, muito superiores às convencionais, sendo a temperatura mínima de $1090^{\circ} \mathrm{C}$, constituindo um processo de pirólise por tocha e plasma. O processo aceita qualquer tipo de RSS; os materiais são decompostos pela alta temperatura da chama de plasma $\left(4000^{\circ} \mathrm{C}\right)$. Os produtos gerados nesse processo reagem com o vapor injetado, transformando-se em substâncias mais simples como metano, hidrogênio, monóxido de carbono e dióxido de carbono. Os materiais não-orgânicos, como metais, vidros, sujeiras entre outros, são fundidos em forma de lava que, ao solidificar, vitrificam-se. Os gases produzidos no processo podem ser utilizados no aquecimento de caldeiras ou na obtenção de metano. A escória gerada é inerte, portanto, não é tóxica nem agressiva ao meio ambiente, servindo para qualquer tipo de agregado ou podendo ser disposta em aterro sanitário (SOUZA, 2011).

Um quadro comparativo das vantagens e desvantagens dos processos térmicos sem oxidação para o tratamento dos RSS, podem ser observadas no Quadro 4;

Quadro 4- Quadro comparativo de vantagens e desvantagens dos processos térmicos sem oxidação para o tratamento de RSS

\begin{tabular}{|c|c|c|}
\hline Tecnologias & Vantagens & Desvantagens \\
\hline Autoclavagem & $\begin{array}{l}\text { Não geração de resíduos tóxicos ou } \\
\text { dispersão de aerossóis (desde que a } \\
\text { autoclave esteja regulada e seja } \\
\text { corretamente operada); } \\
\text { Pode ser utilizado na própria unidade } \\
\text { geradora; } \\
\text { É um processo potente, aceitando a maioria } \\
\text { dos RSS; } \\
\text { Depois de esterilizados os resíduos são } \\
\text { considerados resíduos comuns; } \\
\text { Finalmente tem baixo custo operacional. }\end{array}$ & $\begin{array}{l}\text { Custo alto de aquisição e instalação do } \\
\text { equipamento; } \\
\text { Tempo de aquecimento e resfriamento e } \\
\text { cuidados com a operação; } \\
\text { Custo adicional de transporte e disposição } \\
\text { final em aterros sanitários, e com as } \\
\text { embalagens especiais; } \\
\text { Peso dos resíduos não se altera e os resíduos } \\
\text { não são descaracterizados, embora sejam } \\
\text { inativados biologicamente. }\end{array}$ \\
\hline Microondas & $\begin{array}{l}\text { Alto grau de eficiência; } \\
\text { Menor interferência do homem no processo, } \\
\text { diminuindo os riscos de acidentes. }\end{array}$ & $\begin{array}{l}\text { Custo de implantação superior ao da } \\
\text { autoclave; } \\
\text { Não sendo apropriado para tratar mais de } \\
800 \text { kg de resíduos/dia; } \\
\text { Apresenta riscos de emissões de aerossóis } \\
\text { que podem conter produtos orgânicos } \\
\text { perigosos; } \\
\text { Necessita de pessoal especializado e opera } \\
\text { sob estritas normas de segurança. }\end{array}$ \\
\hline
\end{tabular}

Continua.... 
Quadro 4-Conclusão....

\begin{tabular}{|c|c|c|}
\hline Tecnologias & Vantagens & Desvantagens \\
\hline $\begin{array}{l}\text { Desativação } \\
\text { Eletrotérmica } \\
\text { (ETD) }\end{array}$ & $\begin{array}{l}\text { Ausência de efluentes de qualquer natureza; } \\
\text { Redução de volume de resíduos obtida na } \\
\text { trituração e } \\
\text { Processo contínuo }\end{array}$ & $\begin{array}{l}\text { Custo operacional relativamente alto e } \\
\text { garantia questionável da eficiência do } \\
\text { tratamento dos resíduos, uma vez que há } \\
\text { possibilidade de nem toda a massa de } \\
\text { resíduos ficar exposta aos raios } \\
\text { eletromagnéticos }\end{array}$ \\
\hline Pirólise & $\begin{array}{l}\text { Garantia de eficiência de tratamento; } \\
\text { Redução do volume significativa e } \\
\text { Pode ser aplicado a resíduos infecciosos, } \\
\text { farmacêuticos e químicos }\end{array}$ & $\begin{array}{l}\text { Apresenta elevado custo, exigindo alto } \\
\text { investimento e significativos valores de } \\
\text { operação e manutenção; } \\
\text { Elevado custo no controle e tratamento de } \\
\text { efluentes gasosos e líquidos. }\end{array}$ \\
\hline Plasma Térmico & $\begin{array}{l}\text { Elevadas temperaturas, causando rápida e } \\
\text { completa pirólise, podendo vitrificar certos } \\
\text { resíduos inorgânicos; } \\
\text { Alta densidade de energia; Utilização de } \\
\text { energia elétrica; } \\
\text { Redução a vazão total de gases efluentes e } \\
\text { redução de volume dos resíduos (400:1). }\end{array}$ & $\begin{array}{l}\text { Requer materiais de alta performance nem } \\
\text { sempre existentes no mercado nacional e } \\
\text { Custos elevados de investimentos e } \\
\text { operação. }\end{array}$ \\
\hline
\end{tabular}

Fonte: Adaptado de NOVI, 2013; SOUZA, 2011; PEREIRA, 2012; RIBEIRO, 2008.

\subsubsection{DESINFECÇÃo QUÍMICA}

A desinfecção química é um processo químico que destrói a maioria dos microrganismos patogênicos de objetos inanimados e superfícies, com exceção de esporos bacterianos, definida como um processo de adição de substâncias líquidas desinfetantes aos resíduos, que incluem glutaraldeído $2 \%$, ácido peracético, compostos fenólicos, cloro, álcool 70\%, compostos de amônia quaternária, formaldeído e peróxido de hidrogênio e, mais recentemente o ozônio, visando a quebra dos materiais orgânicos e destruição dos agentes infecciosos. Alguns fatores devem ser levados em conta ao se utilizar a descontaminaçáo química, como: tipo de microrganismo, grau de contaminação e o tipo, concentração e quantidade de desinfetante utilizado, bem como, temperatura, $\mathrm{Ph}$, grau de mistura e a duraçáo do contato do desinfetante com os resíduos contaminados. Existem mais de 8000 produtos registrados como desinfetantes, contudo os materiais amplamente utilizados são os derivados do cloro, como o hipoclorito de sódio - água sanitária doméstica (ARIZA, 2015).

\subsubsection{TRITURAÇÃO MECÂNICA/QUíMICA}

A trituração mecânica/química associa o tratamento químico a trituração mecânica dos resíduos, de forma que ao final do processo há geração de efluente líquido que pode ser descarregado na rede de esgoto, desde que atendam os padróes estabelecidos pela legislação local (ARIZA, 2015).

\subsubsection{ESTERILIZAÇÃO POR GASES}

A esterilização por gases: consiste na utilização de esterilizantes químicos ou germicidas de alto nível, que são antimicrobianos de toxicidade não seletiva, isto é, tóxicos protoplasmáticos, que atuam indiscriminadamente sobre a célula do hospedeiro e do parasito, capazes de destruir bactérias, fungos, vírus e endósporos bacterianos, em intervalo de tempo operacional, que normalmente varia entre quatro e dezoito horas, dependendo do agente utilizado, da espécie microbiana e do número de esporos presentes. Em geral, apesar de adequada para esterilização de resíduos infectantes e perfurocortantes, a esterilização por gases pode apresentar maior eficiência que a esterilização térmica, pois penetra através das embalagens (NOVI, 2013; SINOTI et al., 2009).

Um quadro comparativo das vantagens e desvantagens dos processos químicos para o tratamento dos RSS se encontra abaixo, representado pelo Quadro 5;

Finalmente, uma comparação genérica de critérios importantes das tecnologias para o tratamento de RSS utilizadas no Brasil e no mundo podem ser vistas no Quadro 6; 
Quadro 5 - Quadro comparativo de vantagens e desvantagens dos processos químicos para o tratamento de RSS

\begin{tabular}{|c|c|c|}
\hline Tecnologias & Vantagens & Desvantagens \\
\hline $\begin{array}{l}\text { Desinfecção } \\
\text { química }\end{array}$ & $\begin{array}{l}\text { Baixo custo do processo; } \\
\text { Pode ser realizada na fonte de } \\
\text { geração. }\end{array}$ & $\begin{array}{l}\text { Pode ser ineficaz contra patógenos resistentes a } \\
\text { determinados químicos; } \\
\text { As oportunidades de desinfetar quimicamente o } \\
\text { interior de uma agulha ou de uma seringa são muito } \\
\text { baixas; } \\
\text { Não reduz, nem mesmo descaracteriza os resíduos } \\
\text { tratados, embora se possam triturar os resíduos já } \\
\text { tratados; } \\
\text { A disposição do desinfetante utilizado no sistema de } \\
\text { esgotamento sanitário pode afetar o funcionamento do } \\
\text { tratamento de águas residuais, intervindo no processo } \\
\text { de degradação da natureza. }\end{array}$ \\
\hline $\begin{array}{l}\text { Esterilização por } \\
\text { gases }\end{array}$ & $\begin{array}{l}\text { É muito eficaz e atua a baixa } \\
\text { temperatura } \\
\text { O óxido de etileno, o formaldeído } \\
\text { é um gás esterilizante, que se } \\
\text { decompõe em forma de vapor a } \\
\text { partir de uma solução aquosa de } \\
\text { formol e seus vapores não são } \\
\text { inflamáveis. }\end{array}$ & $\begin{array}{l}\text { O óxido de etileno, gás de efeito bactericida, exige } \\
\text { inúmeros cuidados, pois pode causar queimaduras, } \\
\text { mutagênese e provavelmente carcinógenos, oferecendo } \\
\text { em seu manuseio risco de explosão, tornando a prática } \\
\text { de uso do gás pouco empregada; } \\
\text { Produtos altamente tóxicos e liberar como efluentes, } \\
\text { resíduos mais perigosos que os tratados; } \\
\text { Alto risco ocupacional e ambiental, e custo operacional } \\
\text { relativamente alto. }\end{array}$ \\
\hline
\end{tabular}

Fonte: Adaptado de ARIZA, 2015; NOVI, 2013; SINOTI, 2009.

Quadro 6 - Quadro comparativo de tecnologias para o tratamento de RSS

\begin{tabular}{|c|c|c|c|c|}
\hline $\begin{array}{l}\text { Critérios de } \\
\text { comparação }\end{array}$ & $\begin{array}{l}\text { Autoclave/ } \\
\text { tratamento } \\
\text { térmico úmido }\end{array}$ & $\begin{array}{c}\text { Ondas } \\
\text { eletromagnéticas } \\
\text { (microondas e ondas } \\
\text { de rádio) }\end{array}$ & $\begin{array}{l}\text { Desinfecção } \\
\text { química }\end{array}$ & $\begin{array}{l}\text { Incineração à alta } \\
\text { temperatura }\end{array}$ \\
\hline $\begin{array}{l}\text { Destruição de } \\
\text { microrganismos } \\
\text { infecciosos }\end{array}$ & \multicolumn{3}{|c|}{ Pode alcançar Nível III de destruição (bom) } & $\begin{array}{l}\text { Destrói totalmente } \\
\text { (ótimo) }\end{array}$ \\
\hline $\begin{array}{l}\text { Fatores que afetam } \\
\text { a eficácia }\end{array}$ & $\begin{array}{l}\text { Temperatura e } \\
\text { pressão. } \\
\text { Embalagem } \\
\text { inadequada } \\
\text { Fragmentação para } \\
\text { melhorar a eficácia. } \\
\text { Comprimento do } \\
\text { ciclo de tratamento. } \\
\text { Remoção } \\
\text { incompleta do ar da } \\
\text { câmara. } \\
\text { Tamanho da carga } \\
\text { de resíduos. } \\
\text { Pode demandar } \\
\text { fragmentação } \\
\text { adicional para } \\
\text { destruir objetos } \\
\text { pontiagudos. } \\
\text { Razões éticas contra } \\
\text { a destruição de } \\
\text { partes do corpo }\end{array}$ & $\begin{array}{l}\text { Conteúdo de } \\
\text { umidade } \\
\text { Potência da fonte de } \\
\text { microondas. } \\
\text { Duração da exposição } \\
\text { Composição da } \\
\text { mistura nos resíduos. } \\
\text { Fragmentação para } \\
\text { melhorar a eficácia. } \\
\text { Relatos de que a } \\
\text { eficiência das } \\
\text { microondas decresce } \\
\text { se o conteúdo líquido } \\
\text { dos resíduos for > } \\
10 \% \text { conteúdo de } \\
\text { metais > } \% \text { ou peças } \\
\text { de metal >0,2kg. } \\
\text { Pode demandar } \\
\text { fragmentação } \\
\text { adicional para } \\
\text { destruir objetos } \\
\text { pontiagudos. } \\
\text { Razões éticas contra a } \\
\text { destruição de partes } \\
\text { do corpo. }\end{array}$ & 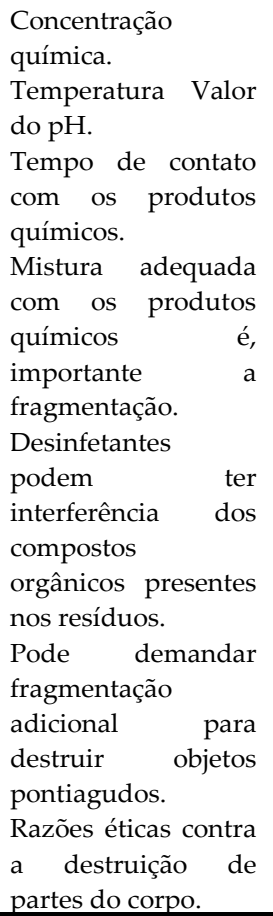 & $\begin{array}{l}\text { Mistura adequada. } \\
\text { Conteúdo de } \\
\text { umidade dos } \\
\text { resíduos. } \\
\text { Enchimento da } \\
\text { câmara } \\
\text { combustão. } \\
\text { Tempo de } \\
\text { permanência. } \\
\text { A incineração } \\
\text { destrói todos os } \\
\text { objetos pontiagudos } \\
\text { e torna os resíduos } \\
\text { irreconhecíveis } \\
\text { A incineração } \\
\text { destrói todas as } \\
\text { partes do corpo e } \\
\text { torna os resíduos } \\
\text { irreconhecíveis }\end{array}$ \\
\hline
\end{tabular}


Quadro 6 - Continuação....

\begin{tabular}{|c|c|c|c|c|}
\hline $\begin{array}{l}\text { Critérios de } \\
\text { comparação }\end{array}$ & $\begin{array}{l}\text { Autoclave/ } \\
\text { tratamento } \\
\text { térmico úmido }\end{array}$ & $\begin{array}{l}\text { Ondas } \\
\text { eletromagnéticas } \\
\text { (microondas e ondas } \\
\text { de rádio) }\end{array}$ & $\begin{array}{c}\text { Desinfecção } \\
\text { química }\end{array}$ & $\begin{array}{c}\text { Incineração à alta } \\
\text { temperatura }\end{array}$ \\
\hline $\begin{array}{l}\text { Impactos no meio } \\
\text { ambiente }\end{array}$ & $\begin{array}{l}\text { Pode gerar } \\
\text { compostos } \\
\text { orgânicos voláteis } \\
\text { tóxicos, } \\
\text { formaldeídos, } \\
\text { vapor de mercúrio e } \\
\text { outras emissões } \\
\text { atmosféricas não } \\
\text { caracterizadas. } \\
\text { Gera odores } \\
\text { desagradáveis e } \\
\text { sujeitos a objeções. } \\
\text { Gera esgoto da } \\
\text { condensação. O } \\
\text { esgoto pode ser } \\
\text { considerado como } \\
\text { resíduo químico e } \\
\text { tratado como tal. }\end{array}$ & $\begin{array}{l}\text { Pode gerar } \\
\text { compostos orgânicos } \\
\text { voláteis tóxicos, } \\
\text { formaldeídos, vapor } \\
\text { de mercúrio e outras } \\
\text { emissões } \\
\text { atmosféricas não } \\
\text { caracterizadas. } \\
\text { Pode ser produzida } \\
\text { uma pequena } \\
\text { quantidade de esgoto } \\
\text { pela condensação. O } \\
\text { esgoto pode ser } \\
\text { considerado como } \\
\text { resíduo químico e } \\
\text { tratado como tal. } \\
\text { Pode gerar odores. }\end{array}$ & $\begin{array}{l}\text { Pode gerar } \\
\text { compostos } \\
\text { orgânicos voláteis } \\
\text { tóxicos, } \\
\text { formaldeídos, vapor } \\
\text { de mercúrio e outras } \\
\text { emissões } \\
\text { atmosféricas não } \\
\text { caracterizadas. } \\
\text { Desinfetantes } \\
\text { podem reagir com } \\
\text { resíduos químicos e } \\
\text { produzir substâncias } \\
\text { químicas } \\
\text { desconhecidas. } \\
\text { Será produzida uma } \\
\text { grande quantidade } \\
\text { de esgoto, } \\
\text { considerado como } \\
\text { resíduo químico e } \\
\text { tratado como tal. }\end{array}$ & 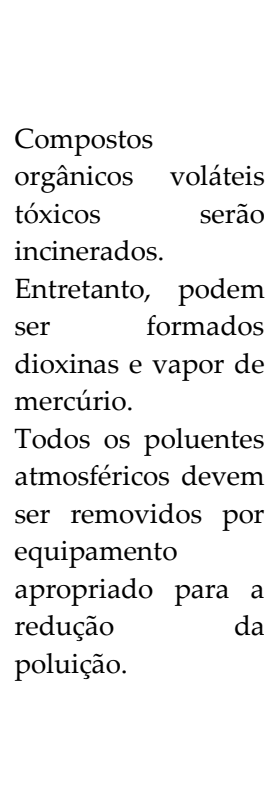 \\
\hline $\begin{array}{l}\text { Redução do } \\
\text { peso/volume dos } \\
\text { resíduos tratados }\end{array}$ & \multicolumn{3}{|c|}{$\begin{array}{l}\text { Não pode reduzir o peso dos resíduos. O peso pode aumentar devido } \\
\text { à adição de destruidor/valor ou produtos químicos. } \\
\text { Não pode reduzir significativamente o volume de resíduos a menos } \\
\text { que seja utilizado fragmentador ou compactador após o tratamento. }\end{array}$} & $\begin{array}{l}\text { A incineração reduz } \\
\text { o peso dos resíduos } \\
\text { em mais de } 90 \% \text {. } \\
\text { A incineração reduz } \\
\text { o volume dos } \\
\text { resíduos } \\
\text { fragmentação. }\end{array}$ \\
\hline
\end{tabular}

Custo de capital e custo operacional

\begin{tabular}{|c|c|c|c|c|}
\hline $\begin{array}{c}\text { Tratamento } \\
\text { adicional necessário } \\
\text { antes da disposição } \\
\text { final }\end{array}$ & $\begin{array}{l}\text { Fragmentação e } \\
\text { compactação/ } \\
\text { enfardamento } \\
\text { antes do envio } \\
\text { para o aterro. } \\
\text { Os resíduos } \\
\text { devem ser secos } \\
\text { ou transportados } \\
\text { em veículos/ } \\
\text { containers } \\
\text { impermeáveis } \\
\text { antes do envio } \\
\text { para o aterro. }\end{array}$ & $\begin{array}{l}\text { Fragmentação } \\
\text { compactação/ } \\
\text { enfardamento antes do } \\
\text { envio para o aterro. } \\
\text { Os resíduos devem ser } \\
\text { secos ou transportados } \\
\text { em veículos/ containers } \\
\text { impermeáveis antes do } \\
\text { envio para o aterro. }\end{array}$ & $\begin{array}{l}\text { Fragmentação e } \\
\text { compactação/ } \\
\text { enfardamento } \\
\text { antes do envio para } \\
\text { o aterro. } \\
\text { Os resíduos devem } \\
\text { ser secos ou } \\
\text { transportados em } \\
\text { veículos/ } \\
\text { containers } \\
\text { impermeáveis } \\
\text { antes do envio para } \\
\text { o aterro. }\end{array}$ & $\begin{array}{l}\text { Fragmentação } \\
\text { compactação/ } \\
\text { enfardamento antes } \\
\text { do envio para o } \\
\text { aterro. }\end{array}$ \\
\hline
\end{tabular}

Deve ser aplicado o princípio do poluidor-pagador. Os custos de capital de instalações com novas tecnologias será muito menor que a incineração com equipamento completo de limpeza de gases. Os custos de operação serão possivelmente similares. Um número de fatores afetará os custos totais e, portanto, deve ser feita uma análise cuidadosa de todos os custos antes de qualquer decisão. Uma tabela de avaliação de custos pode ser encontrada na publicação da OMS produzida por Townend e Pruess (1999).

Os resíduos tratados devem ser depositados em aterros ou incinerados. citotóxicas devem ser adequadamente dispostos. o aterro. 
Quadro 6 - Conclusão....

\begin{tabular}{|c|c|c|c|c|}
\hline $\begin{array}{l}\text { Critérios de } \\
\text { comparação }\end{array}$ & $\begin{array}{l}\text { Autoclave/ } \\
\text { tratamento } \\
\text { térmico úmido }\end{array}$ & $\begin{array}{c}\text { Ondas } \\
\text { eletromagnéticas } \\
\text { (microondas e ondas } \\
\text { de rádio) }\end{array}$ & $\begin{array}{l}\text { Desinfecção } \\
\text { química }\end{array}$ & $\begin{array}{l}\text { Incineração à alta } \\
\text { temperatura }\end{array}$ \\
\hline Outros critérios & $\begin{array}{l}\text { A autoclave é um } \\
\text { método } \\
\text { tradicional de } \\
\text { tratamento de } \\
\text { culturas } \\
\text { microbiológicas } \\
\text { em laboratórios } \\
\text { clínicos. }\end{array}$ & $\begin{array}{l}\text { As instituições médicas } \\
\text { estão familiarizadas com } \\
\text { este método. }\end{array}$ & $\begin{array}{l}\text { Algumas } \\
\text { instalações exigem } \\
\text { desinfetantes } \\
\text { patenteados, o que } \\
\text { pode ser caro e não } \\
\text { flexível no uso de } \\
\text { outros } \\
\text { desinfetantes. }\end{array}$ & $\begin{array}{l}\text { Existe potencial } \\
\text { para a recuperação } \\
\text { de calor. Pode tratar } \\
\text { todos os tipos de } \\
\text { resíduos médicos } \\
\text { sem a necessidade } \\
\text { de uma segregação } \\
\text { rigorosaran nos } \\
\text { hospitais e clínicas. }\end{array}$ \\
\hline
\end{tabular}

Fonte: Adaptado de MAVROPOULOS, 2010; SOUZA, 2011; SINOTI et al., 2009.

\subsection{DISPOSIÇÃo FINAL}

A última etapa do manejo dos RSS é a disposição final, que consiste na disposição de resíduos no solo, previamente preparado para recebê-los, obedecendo a critérios técnicos de construçáo e de operaçáo, e com licenciamento ambiental de acordo com a Resoluçáo CONAMA n. ${ }^{\circ}$ 237/1997 (BRASIL, 1997).

A legislação aplicável estabelece que determinadas classes de resíduos de serviços de saúde demandam algum tipo de tratamento previamente à sua disposição final; no entanto, cerca de $25,7 \%$ dos municípios brasileiros ainda destinaram os RSS coletados sem declarar o tratamento prévio dado aos mesmos, o que contraria as normas vigentes e apresenta riscos diretos aos trabalhadores, à saúde pública e ao meio ambiente (ABRELPE, 2017).

A Lei n. ${ }^{\circ}$ 12.305/2010 propóe uma hierarquia de açóes para a destinação dos resíduos sólidos, visando evitar ao máximo a sua disposição em aterro sanitário, o que deveria ser aplicado exclusivamente aos rejeitos. Entretanto, considerando as evidências dos estudos, sobretudo aqueles que comparam os diferentes tipos de resíduos, particularmente por conta das características microbiológicas similares aos resíduos domiciliares, poderia ser disposto em aterro sanitário sem a necessidade de tratamento prévio (MOL et al., 2017).

No Brasil, são encontradas várias formas de disposição final de resíduos no solo, têm os que dispõem inadvertidamente a céu aberto ou em lixões juntamente com outros resíduos, sendo estas formas danosas de disposição final, podendo provocar a contaminação de mananciais de águas superficiais e subterrâneas e a proliferação de vetores (MAVROPOULOS, 2010).

A preocupação com a disposição final de RSS poderia ser minimizada se os estabelecimentos de saúde desenvolvessem e implementassem Planos de Gerenciamento de Resíduos Sólidos (PGRS). Estes planos promovem a identificação da tipologia e da quantidade de geração de cada tipo de resíduos, além de indicar as formas ambientalmente corretas para o manejo, nas etapas de geração, acondicionamento, transporte, transbordo, tratamento, reciclagem, destinação e disposição final. Este é “... documento requisitado pelos órgãos ambientais para a obtençáo da licença ambiental de diversos tipos de atividades, sendo seu principal objetivo a melhoria contínua da gestão ambiental do empreendimento" (MARCHI \& SILVA, 2018, p. 62).

A necessidade de gerenciamento correto não é uma preocupação que se restringe ao Brasil. Vários estudos são realizados dentro desta perspectiva em diversos países em desenvolvimento. Chethana et al (2014) relatam que em 2011, Bangalore, Índia, os resultados de um estudo exploratório sobre gestão de RSS em pequenos estabelecimentos de saúde indicaram que 20\% dos lares de idosos tinham uma Política de Gestão de Resíduos de Saúde e 62,9\% segregavam os seus resíduos de forma adequada. $\mathrm{O}$ estudo conclui que existem algumas deficiências que justificam medidas de desenvolvimento de sistemas de gerenciamento, incluindo a capacitaçáo de pessoal (CHETHANA, 2014).

Outro estudo analisa as práticas de gerenciamento de resíduos em hospitais indianos de pequeno porte, Este estudo foi realizado em cem hospitais em Dehradun, Índia. Segundo o autor, os pequenos hospitais possuem práticas inapropriadas de gerenciamento de RSS, já que apresentaram maior geração de resíduos (178 g em comparação aos $114 \mathrm{~g}$ dos grandes hospitais), indicando inadequaçáo do manejo dos resíduos de saúde, o que acarreta grave poluição biomédica (PANT, 2012).

As práticas corretas nas açôes de gerenciamento de RSS, relativas à destinação final, incluem a vala séptica, considerada como uma das técnicas de engenharia para aterramento de resíduos infectantes não tratados dos estabelecimentos de saúde. Esta alternativa é utilizada por ser considerada uma destinação simples e econômica, adequada a 
pequenos volumes de resíduos com características infectantes, onde deve ser levado em conta critérios e fundamentos básicos para a adoçáo deste sistema, com o provimento de um efetivo controle do sistema e seus efluentes.

Outra forma de disposiçáo final dos resíduos adotada em cerca de $17 \%$ dos municípios brasileiros que coletam os resíduos de serviço de saúde gerados, é o aterro controlado, que adota alguma precaução tecnológica como o recobrimento das camadas com argila que minimiza os riscos de impactos ao meio ambiente e à saúde pública. Apesar de ser uma técnica menos danosa que o lançamento a céu aberto, não atende totalmente aos critérios técnicos necessários à proteção ambiental presentes num aterro sanitário (SOUZA, 2011).

Segundo a RDC n.o 306/2004 da ANVISA, a maneira de dispor os resíduos de forma segura é o aterro sanitário, definido como a técnica de disposição final de resíduos sólidos urbanos no solo, por meio de confinamento em camadas cobertas com material inerte, segundo normas específicas, de modo a evitar danos ou riscos à saúde e à segurança, minimizando os impactos ambientais. Este tem sido o destino adotado por cerca de $26 \%$ dos municípios brasileiros que coletam seus resíduos de serviço de saúde (ABRELPE, 2017). Esses dados tornam-se preocupantes, uma vez que cerca de $80 \%$ dos municípios coletam dos resíduos de serviço de saúde gerados e que apenas 26\% dos municípios fazem sua destinação em aterros sanitários licenciados, uma parcela expressiva, entre $60 \%$ e $80 \%$ das cidades brasileiras ainda dispóem de maneira inadequada os resíduos de serviço de saúde gerados.

\section{CONCLUSÕES}

Percebe-se, no entanto, que existem inúmeras tecnologias de tratamento de RSS no mercado, tecnologias essas com diferentes características, em termos de custos, segurança ao meio ambiente e à população, entre outros. Nota-se, portanto, que aqueles processos que apresentam custo baixo não são considerados seguros e biodegradáveis e que há necessidade de conhecer todas as características desses processos para que haja uma escolha do tratamento mais adequado, podendo variar essa adequação de acordo com a quantidade de resíduo a ser tratada, não havendo uma só tecnologia de tratamento, já que podem ser mais ou menos adequadas a cada situação.

Apesar de não ser o objetivo deste artigo uma importante recomendação para pesquisas futuras, envolve analisar alternativas de tratamento que sejam técnica e economicamente viáveis tanto para resíduos de serviço de saúde quanto para os resíduos domiciliares, uma vez que os mesmos apresentam características semelhantes. $\mathrm{O}$ aterro sanitário, apesar de ser um projeto de engenharia, operando em condiçóes de reduzir os impactos ambientais quanto à disposição final de resíduos, não pode ser considerado uma opçáo de tratamento de resíduos, e esse armazenamento em massa de resíduos pode se tornar um problema futuro.

Assim, mesmo tendo encerrado suas atividades, um aterro sanitário precisa ser monitorado por aproximadamente quinze anos para coleta e tratamento do chorume e do biogás gerado. Estudos relacionados deveriam contemplar não apenas tratamentos capazes de reduzir o potencial infectante dos resíduos gerados, mas como possibilitar sua eliminação de forma segura. Uma alternativa seria a utilização de incineradores ambientalmente licenciados, economicamente viáveis, capazes de reduzir o volume final dos resíduos de saúde gerados, visando reaproveitamento energético e com eficiente tratamento dos gases.

A análise das alternativas tecnológicas para tratamento e disposição final dos RSS evidenciam que o Brasil e o mundo estáo mais conscientes de que os RSS precisam de tratamento e disposiçáo final para uma gestão adequada.

\section{AGRADECIMENTOS}

A Universidade Católica do Salvador (UCSAL) e ao Grupo de Pesquisa em Gestão Ambiental e Desenvolvimento de Empreendimentos Sociais (GAMDES) coordenado pela Profa. Dra. Cristina M.D. F. Marchi

\section{REFERÊNCIAS}

ABRELPE - Associação Brasileira de Empresas de Limpeza Pública e Resíduos Especiais. Panorama dos Resíduos Sólidos no Brasil. São Paulo, 2017, 64 p.

ANVISA, Agência Nacional de Vigilância Sanitária, Resoluçáo RDC nº 306, de 07 de dezembro de 2004. Disposiçáo sobre o regulamento técnico para o gerenciamento de resíduos de serviços de saúde. Brasília, 2004. 
ANVISA, Agência Nacional de Vigilância Sanitária, Resolução RDC no. 222, de 28 de março de 2018. Regulamenta as boas práticas de gerenciamento dos resíduos de serviços de saúde e dá outras providências. Brasília, 2018.

ARIZA, B. G. Gestáo e gerenciamento de resíduos de serviço de saúde dos grupos “ $A$ ”, " $B$ ” e “ $E$ ” no estado de Goiás. 2015. 94 f. Dissertação (Mestrado em Engenharia do Meio Ambiente) - Universidade Federal de Goiás, Goiânia, 2015. Disponível em: http://repositorio.bc.ufg.br/tede/handle/tede/5211. Acesso em: 03 Abr.2018.

BORG, M. A. Clinical waste disposal: getting the facts right. Journal of Hospital Infection, 2007, v. 65, n.2, p. 178-180

BOSMANS, L.; HELSEN, L. The crucial role of Waste-to-Energy technologies in enhanced landfill mining: a technology review. Journal of Cleaner Production, [s.1.], v.55, p.10-23, set 2013. Elsevier BV. http://dx.doi.org/101016/j. jclepro.2012.05.032.

BRASIL. Lei Federal no 12.305 de 12 de agosto de 2010. Política Nacional de Resíduos Sólidos. Brasília: MMA, 2010. Disponível em: <http://www.camara.gov.br/sileg/integras/501911.pdf>. Acesso em: 03 Abr.2018.

BRASIL. Ministério do Trabalho e Emprego. Riscos Biológicos: guia técnico. Os riscos biológicos no âmbito da Norma Regulamentadora no 32. Brasília, 2006.

BRASIL. Resolução CONAMA no 237 de 5 de agosto de 1997. Dispóe sobre a revisão e complementação dos procedimentos e critérios utilizados para o licenciamento ambiental. Brasília, 1997.

BRASIL. Resoluçáo CONAMA no 358 de 29 abril de 2005. Dispóe sobre o tratamento e a disposição final dos resíduos dos serviços de saúde e dá outras providências. Brasília, 2005.

CHAMON, R. C.; CARDOSO, R.; BARROS, C. F. Tratamento de Resíduos Sólidos Urbanos, introduzindo uma nova tecnologia para o cenário brasileiro: Pirólise Lenta a Tambor Rotativo. I Congresso Fluminense de Engenharia, Tecnologia e Meio Ambiente - UFF. Niterói-RJ. 2013.

CHETHANA T; THAPSEY H; GAUTHAM MS; SREEKANTAIAH P; SURYANARAYANA SP. Situation analysis and issues in management of biomedical waste in select small health care facilities in a ward under Bruhat Bengaluru Mahanagara Palike, Bangalore, India. J Community Health. 2014 Apr;39(2):310-5. DOI: 10.1007/s10900-013-97612. Disponível em: https://www.ncbi.nlm.nih.gov/pubmed/23982773. Acesso em: 03 Abr.2018.

COUTINHO, R. M. C.; COUTINHO, A. L. O; CARREGARI, L. C. Incineração: Uma Alternativa Segura para o Gerenciamento de Resíduos Sólidos. Advances in Cleaner Production, 2011.

DIAZ, L. F., SAVAGE, G. M. \& EGGERTH, L. L. Alternatives for the treatment and disposal of healthcare wastes in developing countries. Waste Management 25, (2005): 626-637.

FERREIRA, A. Z. G. Aproveitamento Energético de Resíduos Sólidos Urbanos pelo Processo de Incineração: Análise Técnica e Ambiental. Conexáo Academia A Revista Científica Sobre Resíduos Sólidos, v.4, ano II, p.9-17, jul. 2013.

FILHO, A. T.; FERREIRA, A. F. M.; Melo, G. C. B. de; LANGE, L. C. Tratamento de Resíduos de Serviços de Saúde pelo processo de pirólise. Engenharia Sanitária Ambiental, v.19 n.2, abril/junho 2014, 187-194.

GEITENES, Ana Paula Mendes. Alternativas tecnológicas para o tratamento e disposição final dos resíduos de serviços de saúde. In: MARCHI, Cristina Maria Dacach Fernandez. Gestáo dos Resíduos Sólidos: conceitos e perspectivas de atuação, 1. ed., Curitiba: Appris Ltda, 2018.

KÜHL, R. M.; MUNIZ, R. N.; BRASILEIRO, B. C.; SOUZA, N. P.; NETO, P. C. R.; CRUZ, M. SÁ, J. A. S.; ROCHA, B. R. P. Tecnologias para tratamento térmico de resíduos sólidos: Uma abordagem energética. In: $10^{\circ}$ Congresso Internacional de Bionergia. Sáo Paulo-SP. 2015. 
MAIA, C. M. B. F; MADARI, B. E.; NOVOTNY, E. Advances in biochar research in Brazil. Dynamic Soil, Dynamic Plant. 5 (Special Issue 1), p. 53-58, 2011.

MARCHI, Cristina Maria Dacach Fernandez; SILVA, Mayara. Elaboração dos Planos de Gerenciamento de Resíduos Sólidos: Apoio à Gestão Pública. In: MARCHI, Cristina Maria Dacach Fernandez. Gestáo dos Resíduos Sólidos: conceitos e perspectivas de atuação, 1. ed., Curitiba: Appris Ltda, 2018.

MARTINI, A. A. Estudo de alternativa de valorizaçáo de resíduos de saúde advindos de processo de desinfecçáo por desativaçáo eletrotérmica (ETD). (Mestrado) Faculdade de Saúde Pública, Universidade de Sáo Paulo, São Paulo: 2016.

MAVROPOULOS, A. Estudo para gestáo de Resíduos de Serviços de Saúde no Brasil. Relatório Final. EPEM SA. Set. 2010. 71 p. Disponível em: <http://www.abrelpe.org.br/arqui-vos/estudo_gestao.pdf>. Acesso em: 03 Abr.2018.

MOL, M. P. G.; CUSSIOL, N. A. DE M.; HELLER, L. Destinação de resíduos de serviços de saúde do subgrupo A4: política baseada em evidência ou em intuiçāo? Eng. Sanit. Ambient. [Online]. 2017 vol.22, n.6, pp.1037-1041. Epub Aug 03, 2017. ISSN 1413-4152. http://dx.doi.org/10.1590/s1413-41522017152421

NOVI, J. C.; OLIVEIRA, S. V. W. B.; JUNIOR, A. P. S.; BONACIM, C. A. G; OLIVEIRA, M. M. B. Avaliaçăo legal, ambiental e econômica da implantaçáo de sistema próprio de tratamento de Resíduos de Serviços de Saúde para geraçáo de energia em hospital-escola do Estado de São Paulo. Desenvolvimento e Meio Ambiente, v. 27, p. 193-209, jan./jun. 2013.

PANT D. Waste management in small hospitals: trouble for environment. Environ Monit Assess. 2012 Jul; 184(7):4449-53. DOI: 10.1007/s10661-011-2276-3. Epub 2011 Aug 4. Disponível em: https://link.springer.com/articl e/10.1007\%2Fs10661-011-2276-3. Acesso em: 03 Abr.2018.

PEREIRA, E. A.; SILVA, K. A.; SOUZA, H. A. Tratamento dos resíduos sólidos de serviço de saúde através de micro-ondas. III Congresso Brasileiro de Gestáo Ambiental. Goiânia-GO. 2012.

REICHERT, F. R. Relatório Tecnologias para Aproveitamento Energético dos Resíduos. INNOVA Energias Renováveis. Rio de Janeiro, RJ. 2012.

RIBEIRO, C. DA S. Análise das tecnologias de tratamento de resíduos biológicos de serviço de saúde em hospitais públicos no Município do Rio de Janeiro. Dissertação de Mestrado apresentada à Escola Nacional de Saúde Pública Sergio Arouca. Rio de Janeiro: s.n., 2008.

SILVA, et al. Regulamentaçáo do tratamento dos Resíduos infectantes em serviços de saúde: uma revisão de literatura. Revista Brasileira de Ciências Ambientais. Bahia, 2011. Disponível em: http://www.abes-dn.org.br/publicacoes/ rbciamb/PDFs/22-06_Materia_4_final_artigos287.pdf. Acesso em: 03 Abr.2018.

SINOTI, A. L. L.; FALCO JUNIOR, I.; SOUZA, S. B. O descarte de medicamentos: um estudo comparativo da problemática no Brasil, EUA e Europa. 62 f. Trabalho de Conclusão de Curso de Especialização em Toxicologia Aplicada à Vigilância Sanitária, Universidade Estadual de Londrina, Londrina, 2009.

SOUZA, Alexandre Pereira. Análise da Capacidade Atual de Tratamento e Disposiçáo Final de Resíduos de Serviço de Saúde Gerados no Estado do Rio de Janeiro, com Recorte da Regiáo Hidrográfica do Guandu. Rio de Janeiro: UFRJ/COPPE, 2011.

TÔRRES FILHO, A.; FERREIRA, A. F. M.; MELO, G. C. B.; LANGE, L. C. Tratamento de Resíduos de Serviços de Saúde pelo processo de pirólise. Eng. Sanit. Ambiental v. 19, n. 2, p. 187-194, 2014.

WHO - World Health Organization. Wastes from healthcare activities. 2015. Disponível em: <http://www.who.int/ mediacentre/factsheets/fs253/en/>. Acesso em: 03 Abr.2018. 